\title{
Seasonally dependent morphological variations of circulating hemocytes in Helix pomatia
}

\author{
Damir Suljević* , Erna Islamagić, Filip Filipić, Muhamed Fočak \\ Department for Biology, Faculty of Science, University of Sarajevo, 71000 Sarajevo, Bosnia and Herzegovina \\ ${ }^{\star}$ Corresponding author, E-mail: suljevic.damir@gmail.com
}

\begin{abstract}
Total number and types of hemocytes were analysed in hemolymph of Roman snail (Helix pomatia L.). Significant differences in the number and types of hemocytes during the season at different locations were identified. The average number of hemocytes ranged from 154 to 288 per $10 \mu \mathrm{L}$ of hemolymph. The highest number of hemocytes was recorded in snails at higher altitudes. Significant intergroup differences between all sites were identified. The most numerous hemocytes were granulocytes, followed by agranulocytes, while hyalinocytes were the least common in the post-hibernation period. Post hoc analysis showed certain intragroup differences for most locations except for comparison between wet habitat and habitats with anthropogenic influence, and between wet habitats and urban place with wet vegetation. A large number of transformed hemocytes in the encapsulated phase were identified in snail hemolymph infected with flat worms. Our results represent the first record of data for the number of hemocytes in molluscs and the first data for hemocytes of Helix pomatia. Further investigations and development of a uniform classification of hemocytes and their role in the immune response would be necessary in the future.
\end{abstract}

Key words: granulocytes, Helix pomatia, hemocytes, hemolymph, hyalinocytes.

\section{Introduction}

Hemocytes in molluscans occur in circulating hemolymph and are involved in many biological processes such as tissue reparation, nutrition and shell building (Batistella et al. 1996). On the other hand, one study suggested that hemocytes significantly participate in the immune response, and thus they are often named „immunocytes“ (Matozzo, Gogné 2016). The classification of hemocytes is not uniform due to different criteria, although today it is accepted that in molluscans (like bivalves), hemocytes are categorized into two groups: granulocytes and hyalinocytes (Matozzo, Gogné 2016; Pila et al. 2016).

However, in gastropods three types of hemocytes have been identified:agranular (semigranular), granular cells and hyaline cells (Martin et al.2007). A more recent classification includes: agranulocytes (hyaline cells), granulocytes, and small immature spherical cells (prohemocytes) (Cossarizza et al. 2005). This classification is supported by recent flow cytometric and electron microscopic analysis (Cossarizza et al. 2005), even though lack of specific cell markers makes it difficult to establish a more precise classification. Variation in hemocyte types occurs due to functionality of different morphological types (Pila et al. 2016). In general, all cells carry out the phagocytosis process, excepting for the immature form of hemocytes (Barracco, Steil 1993; Malagoli 2018). Mainly, granular hemocytes are phagocytes (Limnaea) with primarly location in connective tissue of different organs (Boisseaux et al.2016). In the genus Haliotis, hyaliocytes are predominant and take over the functions of other cells, like adhesion and phagocytosis (Sahaphong et al. 2001). After stimulation of immune response, hyaline and granular cells are acivated in freshwater snails, like in genera Biomphalaria and Haliotis (Donaghy et al. 2010; Calvacanti et al. 2012); hyalinocytes are more numerous, but their precise role in defense against different antigens has not been invesigated yet.

In molluscans, seasonal variation of hemocyte number during cellular defenses have been determined mainly in bivalves like oyster Crassostrea virginica. Hemocyte bactericidal activity and mean hemocyte number in oyster hemolymph was observed to be significantly higher in warmer months compared to winter months (Volety et al. 1999). Also, it has been observed that environmental changes had impact on the transmission of many parasitic diseases in snails, consequently leading to numerical changes in different types of hemocytes (Liang et al. 2007; Oliviera et al. 2010). The presence of heavy metals and pesticides in the environment also affects lysosome instability and affects hemocyte number (Molnar, Fong 2012). Possibly, different physiological processes, like hibernation, can result in changes of hemocyte number, due to activation of alternative physiological processes. The first data regarding protein and mineral concentration during hibernation were obtained in the species Helix pomatia, where total proteins, albumins, globulins, $\mathrm{Ca}^{2+}$ 
and $\mathrm{K}^{+}$concentrations were measured at the beginning of hibernation, end of hibernation and posthibernation period (control group), which might be associated with different amounts of hemocytes (Suljević et al. 2017). Overall, hemocyte numbers in molluscan that live under different environmental conditions have been mainly described in bivalves and classification of hemocytes is based mainly on morphological, cytochemical and functional characteristics (Matozzo, Gogné 2016; Smith et al. 2016). However, there are no available data regarding number of hemocytes in the hibernation period and limited data are present regarding their functions in snails, like Roman snail. It is considered that all hemocyte populations are not fully investigated and their types are not completely distinguished (Smith et al. 2016).

Since snails have great importance for the economy, health and environment, we decided to examine the effect of environmental factors on hemocyte number, which is an indicator of the snail's health state. In the natural microenvironment they are under different stressful pressures, which directly result in changes of number of hemocytes that are mainly responsible for innate immune defense system of the snail. Given the increasing environmental pollution, the health status of the snails shown by the number of hemocytes may be an indicator of the level of pollution in the environment. Additionally, limited data are available regarding type and number of hemocytes in Roman snail after a period of hibernation, when snails are exposed to drastic temperature changes in the environment.

The aim of this study is to determine the total hemocyte number and hemocyte types in the Roman snail Helix pomatia, whose life cycle occurs under different environmental conditions, such as higher altitude and different types of habitats. Also, number and types of hemocytes were determined in the post-hibernation period, when hemocytes are extremely active due to the initiation of various physiological processes after awaking.

\section{Materials and methods}

\section{Sampling}

Total number of circulating hemocytes and percentage of different hemocyte types in Roman snail (Helix pomatia L.) hemolymph was determined in this study. The research was carried out at five different locations in the wider area of Sarajevo, Bosnia and Herzegovina, in the period from April 2018 to June 2018. Locations were selected at different altitudes $(511,697,850 \mathrm{~m})$. Vegetation at locations was divided into two groups: vegetation of dry habitats and vegetation of wet habitats, according to their ecological characteristics.

Characteristics of locations included in this study are presented in Table 1. The sampling from location $\mathrm{V}$ was performed twice, because the hibernation period of the snails on the mountain ended later. The in situ collected specimens with random sample method were transferred to the laboratory and analysed during the same day. Overall, 60 individuals were analysed (10 individuals per each location). All snails were between four and five years old according to the relationship between number of layers at the lip and age. A total of $80 \%$ of snails had between two and nine layers The "year" used to determine growth class was assumed to begin in midsummer when a new layer is visible.

\section{Weighing of snails and hemolymph extraction}

Weighing of the snails was done on an analytical scale (with two decimal places). Non-invasive hemolymph extraction was performed from the pericardial area. The selected portion of the shell was disinfected with $70 \%$ isopropylalcohol prep pads (Romed, Netherlands). A part of the shell with size $10 \mathrm{~mm}^{2}$ was removed using a monoscope magnifier (Voyager 10-25x42). The hemolymph collection was performed by needle $(0.90 \times 38 \mathrm{~mm}, 20 \mathrm{Gx} 11 / 2$, Romed, Netherlands) through the pericardial cavity. A total of 0.5 $\mathrm{mL}$ of hemolymph was used for the analysis. All analysis were done in accordance with the Universal Declaration on Animal Welfare and animals were returned to their natural habitat after research.

\section{Analysis of total hemocyte number}

A combined method for counting blood cells in a Nauber's hemocytometer was used for the analysis of circulating hemocytes number. Giemsa stain $(10 \mu \mathrm{L})$ was added in a volume of $40 \mu \mathrm{L}$ of hemolymph ( 0.8 dilution factor). The solution was gently stirred and left for $5 \mathrm{~min}$ at room temperature to allow hemocytes to dye. A volume of $10 \mu \mathrm{L}$ of diluted hemolymph was used for counting. Counting of cells was done using bright field microscope Olympus

Table 1. Locations of snail sampling and their ecological characteristics

\begin{tabular}{llll} 
Location & Date of collection & Altitude $(\mathbf{m})$ & Characteristics \\
\hline I & 09.04 .2018 & 511 & Urban place, vegetation of wet habitats with anthropogenic influence \\
\hline II & 09.04 .2018 & 511 & Urban place, vegetation of dry habitats with anthropogenic influence \\
\hline III & 19.04 .2018 & 511 & Urban place, vegetation of wet habitats with anthropogenic influence \\
IV & 25.04 .2018 & 697 & Urban place, vegetation of wet habitats with anthropogenic influence \\
V1 & 08.05 .2018 & 850 & Meadow, vegetation of wet habitats without anthropogenic influence \\
V2 & 01.06 .2018 & 850 &
\end{tabular}


Table 2. Total mass (in grams) of the snails collected at different locations. ANOVA - Sig.; Tukey test - significant intragroup differences (I-V1); vs - versus; * Statistically significant values at 0.05

\begin{tabular}{|c|c|c|c|c|c|}
\hline \multirow[t]{2}{*}{ Location } & \multirow[t]{2}{*}{ Mean } & \multirow[t]{2}{*}{ Range } & \multicolumn{2}{|c|}{ Shapiro Wilk test } & \multirow[t]{2}{*}{ Tukey tes } \\
\hline & & & Statistics & Sig. & \\
\hline I & $18.53 \pm 1.35$ & $16.19-20.42$ & 0.949 & 0.617 & II vs I \\
\hline II & $13.10 \pm 2.19$ & $8.45-15.93$ & 0.944 & 0.553 & II vs III \\
\hline III & $18.99 \pm 1.34$ & $16.38-21.22$ & 0.988 & 0.999 & II vs IV \\
\hline IV & $17.52 \pm 1.68$ & $14.86-21.09$ & 0.952 & 0.661 & II vs V1 \\
\hline V1 & $13.02 \pm 3.70$ & $7.50-21.40$ & 0.934 & 0.429 & V1 vs I \\
\hline Sig. (I - V1) & & $0.00^{*}$ & & & V1 vs III \\
\hline V2 & $12.84 \pm 2.55$ & $9.66-17.94$ & 0.923 & 0.437 & V1 vs IV \\
\hline Sig. (V1 - V2) & & 0.49 & & & \\
\hline
\end{tabular}

BX41. The number of hemocytes was determined in $10 \mu \mathrm{L}$ of solution multiplied with dilution.

\section{Differential hemocyte counting}

A hemolymph smear was used to differentiate types of hemocytes. The smear was prepared by applying two drops of hemolymph onto the microscope slide and spreading evenly over the entire surface using a glass stick. The prepared smear was air-dried for 30 minutes. After drying, fixation for 5 min was performed by using $99.8 \%$ p.a. methanol (Semikem, Sarajevo, Bosnia and Herzegovina). The residue of methanol was removed by turning the slide at an angle of $45^{\circ}$ and left to dry well at room temperature for $15 \mathrm{~min}$. The slide was then dyed by Giemsa stain for $20 \mathrm{~min}$. The hemocyte differentiation was determined undermicroscope $1000 \times$ magnification (Olympus BX41) at total count of 100 cells.

\section{Statistical analysis}

Mean value, standard deviation and range as descriptive statistical parameters were determined for all parameters. ANOVA variance analysis was used to test the intergroup differences, while intragroup differences were determined by Post Hoc Tukey test. All analyses were made using the IBM SPSS Statistics 20 software package.

\section{Results}

Table 2 illustrates the mass values as mean and standard deviation including the range for analysed snails from the five locations. The Shapiro Wilk test indicated differences to a normal data distribution for the mass of the investigated individuals. Locations I, II, III, and IV were compared by ANOVA to location V, because sampling of the snails was performed in the same period of time. Additionally, comparison between location V1 and V2 was done due to fact that snails were collected from the same location, but in different periods of time.

The average snail mass ranged from 12.84 to $18.99 \mathrm{~g}$. The snails from the higher altitude (location V1 and V2) and also the snails from dry habitats (location II) had the smallest mass Among all groups the ANOVA test showed statistically significant differences (0.00). The Tukey test showed some statistically significant differences between groups. There were differences between site II (dry habitat) and all other (wet habitats), also differences were detected between sites at lower altitudes (location I, II, III, IV) and higher altitude (location V1). Significant differences in mass were not found between group V1 and group V2, probably because the individuals originated from the same site but were collected in different time periods.

Table 3 illustrates the number of circulating hemocytes

Table 3. Total number of circulating hemocytes in snails hemolymph by location. ANOVA - Sig.; Tukey test - insignificant intragroup differences (I-V1); vs - versus; ${ }^{*}$ Statistically significant values at 0.05

\begin{tabular}{|c|c|c|c|c|c|}
\hline \multirow[t]{2}{*}{ Location } & \multirow[t]{2}{*}{ Mean $(10 \mu \mathrm{L})$} & \multirow[t]{2}{*}{ Range $(10 \mu \mathrm{L})$} & \multicolumn{2}{|c|}{ Shapiro Wilk test } & \multirow[t]{2}{*}{ Tukey test } \\
\hline & & & Statistics & Sig. & \\
\hline I & $188.00 \pm 10.06$ & $169-203$ & 0.951 & 0.648 & I vs III \\
\hline II & $154.00 \pm 9.71$ & $139-170$ & 0.959 & 0.776 & I vs IV \\
\hline III & $180.17 \pm 10.00$ & $162-199$ & 0.989 & 0.997 & \\
\hline IV & $202.50 \pm 9.39$ & $185-217$ & 0.961 & 0.798 & \\
\hline V1 & $288.33 \pm 18.49$ & $259-320$ & 0.974 & 0.945 & \\
\hline Sig. & $0.00^{*}$ & & & & \\
\hline V2 & $218.40 \pm 16.37$ & $198-245$ & 0.932 & 0.928 & \\
\hline Sig. (V1-V2) & $0.00^{*}$ & & & & \\
\hline
\end{tabular}


Table 4. Different types of hemocytes by locations. ANOVA - Sig.; Tukey test a,b. The combination of the same letters $\left(^{*}\right)$ among the groups does not show significant differences; vs - versus; ${ }^{* *}$ Statistically significant values at 0.05

$\begin{array}{lccc}\text { Location } & \text { Hyalinocytes } & \text { Agranulocytes } & \text { Granulocytes } \\ \text { I } & 5.73 \pm 1.44^{\star} \mathrm{a} & 37.45 \pm 3.90 & 56.82 \pm 3.92^{\star} \mathrm{b} \\ \text { II } & 7.75 \pm 1.42^{\star} \mathrm{b} & 11.42 \pm 2.43^{\star} \mathrm{a} & 80.83 \pm 3.30^{\star} \mathrm{a} \\ \text { III } & 10.83 \pm 2.29 & 31.83 \pm 3.19 & 57.33 \pm 3.55^{\star} \mathrm{b} \\ \text { IV } & 6.50 \pm 1.45^{\star} \mathrm{a} / \mathrm{b} & 28.08 \pm 3.18 & 65.42 \pm 3.26 \\ \text { V1 } & 4.58 \pm 1.44^{*} \mathrm{ab} & 14.75 \pm 2.83^{*} \mathrm{a} & 80.67 \pm 3.47^{\star} \mathrm{a} \\ \text { Sig. (I-V1) } & 0.00^{* *} & & 75.00 \pm 2.36 \\ \text { V2 } & 4.50 \pm 1.08 & 0.00^{* *} & 0.00^{\star *}\end{array}$

according to the location where snails were collected.

The average number of hemocytes ranged from 154 to 288. The highest number of hemocytes was recorded in snails at higher altitudes, and the lowest in dry habitats (location II). Significant intergroup differences among all sites were identified (0.00). Post hoc analysis showed differences between most locations except for comparison between location I and III and between location I and IV. When we compared group V1 and V2, significant reduction in the number of hemocytes was found after a short period of time (Sig. group V2 $=0.00$ ).

Table 4 presents individual types of hemocytes. Three groups of hemocytes were identified: granulocytes, agranulocytes and hyalinocytes.

In analysed snails we have found three types of hemocytes: hyalinocytes, agranulocytes and granulocytes. Different types of hemocytes were distinguished by light microscopy based on the presence or absence of cytoplasmic granules. Cytoplasmic granules were present in the cytoplasm of granulocyts, absent in agranulocytes and hyalinocytes had few or none. Agranulocytes were the smallest cells compared to other types of hemocytes. They had dark blue nucleus, dark red cytoplasm and high $\mathrm{N} / \mathrm{C}$ ratio. Hyalinocytes were larger than granulocytes and had a smaller N/C ratio. Cytoplasm of hyalinocytes was brighter than cytoplasm of granulocytes. In several cases of granulocytes, cytoplasmic processus similar to pseudopodia have been found.

In snails at all locations, hyalinocytes had the smallest count, followed by moderate number of agranulocytes and the highest for granulocytes. Snails from the second location had the smallest number of agranulocytes and the highest number of granulocytes among all analysed locations. Significant differences were found for all types of hemocytes (hyalinocytes, agranulocytes and granulocytes) among the locations. The Tukey test showed no significant difference in granulocyte count between groups II and V1, and also between groups I and II, while for agranulocyte counts significant differences were not found between groups II and V1 of snails. There was no significant difference in number of hyalinocytes between locations: I and IV, I and V1, II and IV. There was a significantly higher number of agranulocytes and a lower number of granulocytes at location V2 compared to V1.

Fig. 1 to 3 show normal hemocytes in snail hemolymph, while Fig. 4, present transformed hemocytes-immunocytes (scale bar $20 \mu \mathrm{m}$ ).
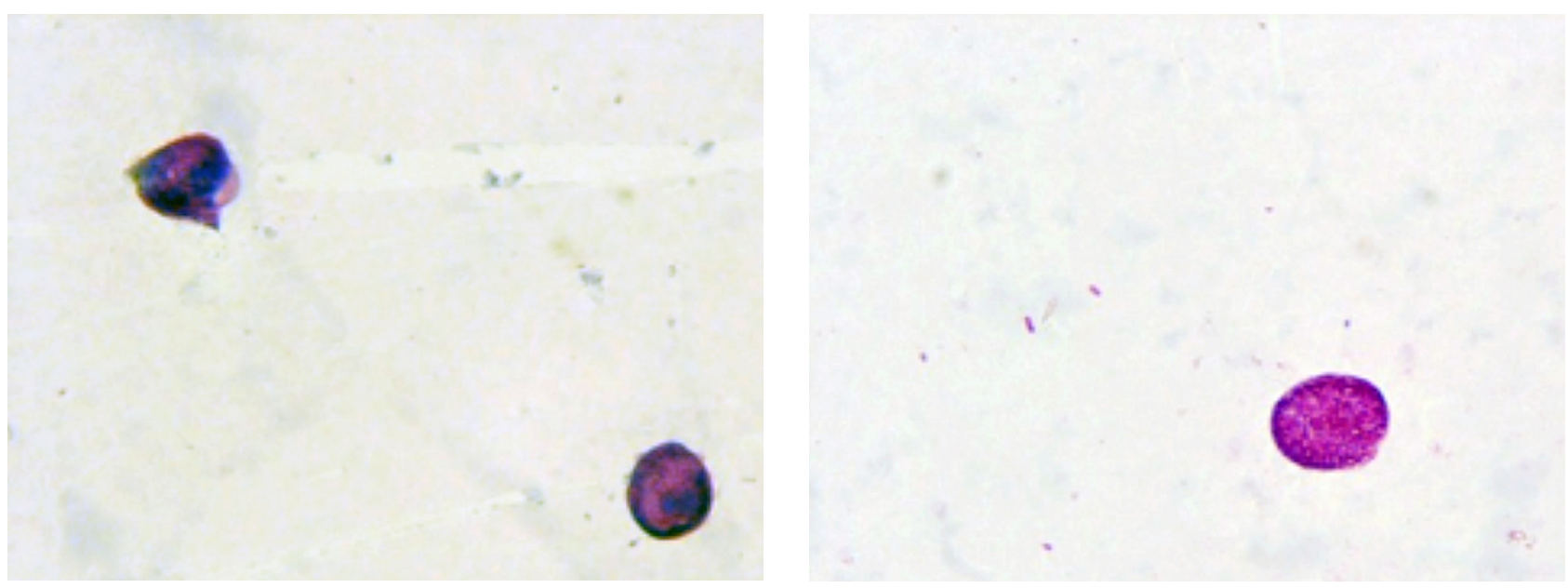

Fig. 1. Granulocytes in hemolymph of Roman snail. 


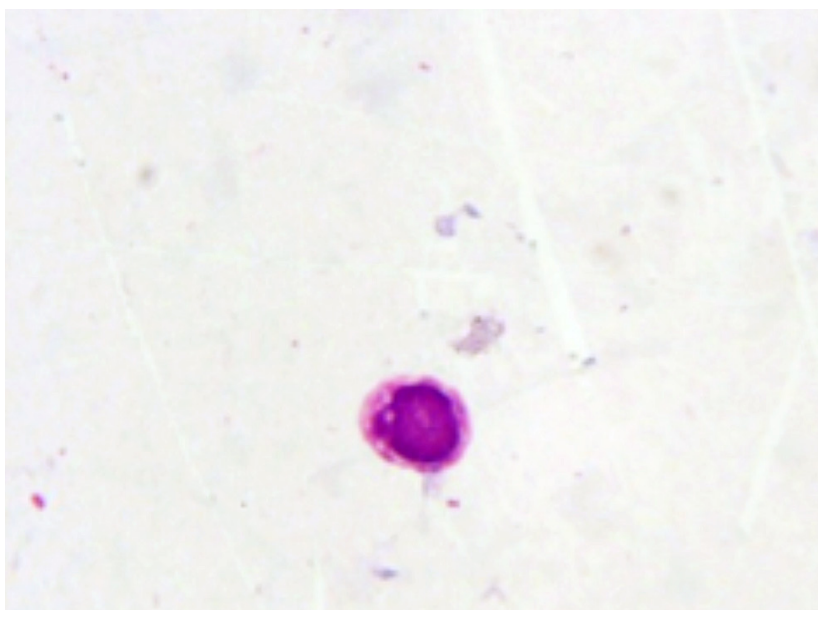

Fig. 2. Hyalinocytes in hemolymph of Roman snail.

\section{Discussion}

Research of hematopoesis in invertebrates was conducted in organisms that served as developmental and immunological models. Hemocyte development in molluscs is not quite understood and researches on signaling pathways and endogenous factors for hemocyte development gave significant progress in this area (Jemaa et al. 2014). Many recent studies distinguish different classes of hemocytes according to different criteria (granularity, cell size, cell surface, etc.) and different classifications due to the lack of biological markers to distinguish specific cell lines and maturation phases. These aspects are unexplored in other invertebrates. In many gastropods, the production of hemocytes takes place in the pericardial cavity (Gagnaire et al. 2008). Sampling of hemolymphs in our study, as well as the identification of hemocytes, was made from the pericardial cavity. Studies on morphological characteristics of circulating immunological cells in the early 1990-ies have progressed to studies of many growth factors and

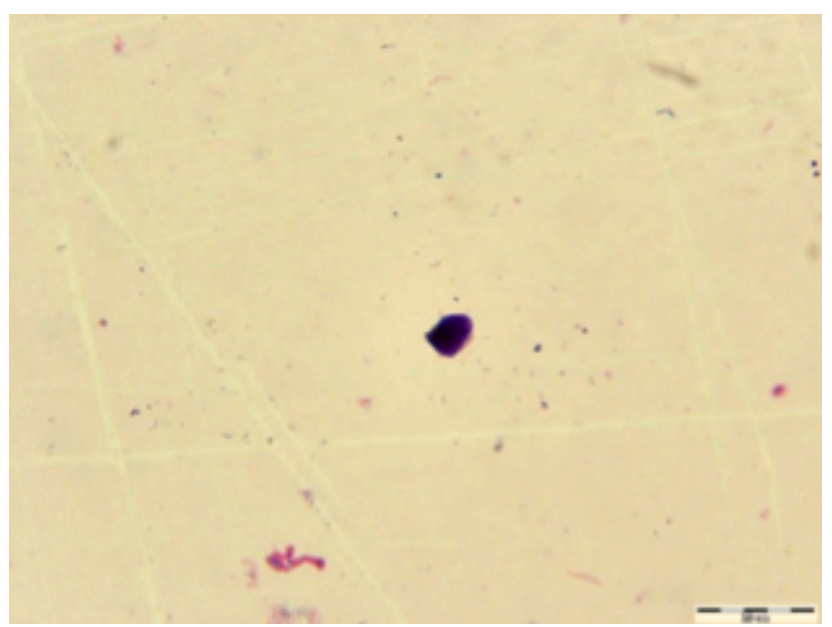

Fig. 3. Agranulocyte in hemolymph of Roman snail.

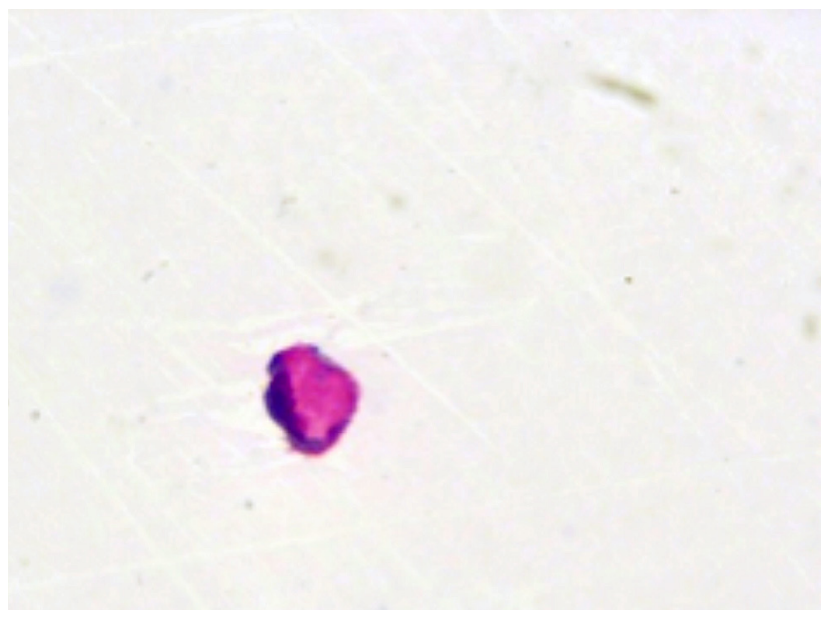

expression of genes that regulate the development of molluscan hemocytes (Pila et al. 2016).

Gastropods are vector hosts of many nematodes and other parasites (Lokero 2010). The development of hemocytes in the gastropoda is well known today mainly for species of high medical or veterinary significance, such as Biomphalaria glabrata. This species is host to Schistosoma mansoni which causes schistosomiasis in humans, so the relationship between snails and larvae of trematodes is the key for the current understanding of the hemocyte functions in the gastropoda (Littlewood, Bray 2001). According to Castellanos-Martínez et al. (2014) there are two classes of hemocytes: granulated and agranulated lymphocytes. Research carried out later on this species indicated three types of hemocytes, classified as large, medium and small hemocytes (Matricon-Gondran, Letocart 1999). Karuthapandi (2010) reported two types of hemocytes (granulocytes and agranulocytes) in the Achatina fulica. In a study performed by Cuet et al. (2015), transmission electron microscopy was used to discover three types of circulating

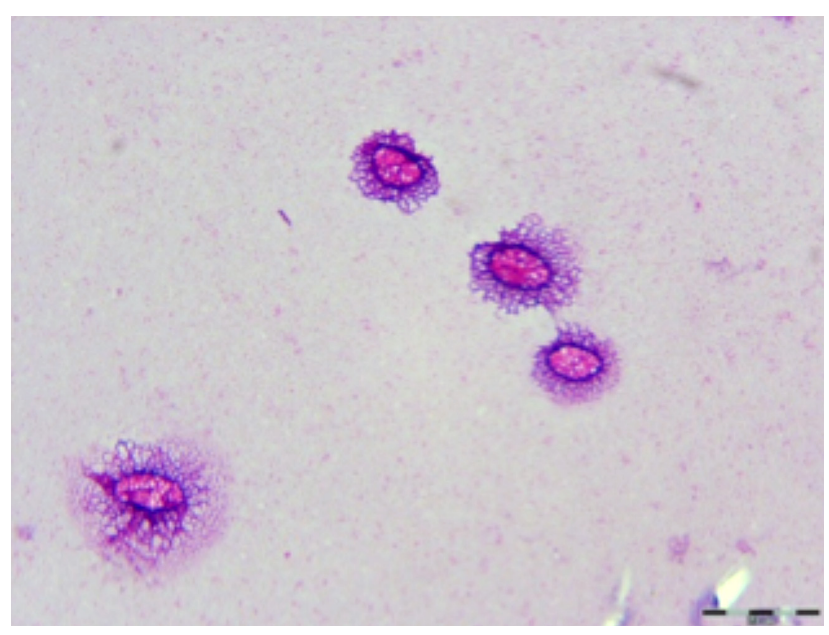

Fig. 4. Transformed hemocyte (immunocyte) during parasitic invasion in hemolymph of Roman snail. 
hemocytes: hyalinocytes, agranulocytes and granulocytes. These three types of hemocytes were previously identified in Pomacea canaliculata (Accorsi et al. 2013). Our study about hemolymph in Helix pomatia provided information about all types of hemocytes. Hyalinocytes are cells with hardly noticeable granulation. Agranulocytes are the smallest cells, usually dark-colored with standard staining and have round and remarkable nucleus. The most numerous and largest cells are granulocytes, which show several stages of development. Immature cells have a large nucleus that fills over $90 \%$ of the cytoplasm with heterogeneous segments. Ocurrence of hyalinocytes in Helix pomatia was very low in contrast to that in Pomacea canaliculata, while the number of granulocytes in our study was very high in relation to this species.

Granulocytes are listed as the most abundant cells in molluscs and their increased number can be a consequence of a period that coincides with awakening or exiting from hibernation. The increase in the number of hemocytes during the post-hibernation period correlates with the increase in number of granulocytes, which have many roles. The expression of fibrinogen-bounded protein (FREP3) in Biomphalaria glabrata increases the number of hemocytes in the presence of parasitic larvae Schistosoma mansoni. This leads to an increase in encapsulation for phagocytosis of parasites (Ataev, Coustau 1999). Infected individuals have a large number of hemocytes that have been transformed and normal hemocytes were observed very rarely in our study. Thus, the increase in the number of hemocytes is a consenquence of presence of parasite, which is manifested by production of all hemocytes that are in the encapsulation phase, which justifies the name „immunocytes“. Very heterogeneous number of hemocytes in all individuals from different locations could be result of many ecological factors, particularly humidity and altitude. There are no recent data in literature about number of hemocytes in Roman snail Helix pomatia. Snails that live at higher altitudes and under higher humidity had the highest number of hemocytes, in comparison to those that live in dry habitats, according to our results. It is interesting that a similar pattern ocurred for type of identified hemocytes: granulocytes were the most numerous cells, followed by agranulocytes, while the lowest number of the hemocyte population was for hyalinocytes.

However, significant differences were identified among all groups, which is related to the influence of external factors. Changes in numbers, morphology and types of hemocytes can be a result of interaction of abiotic and biotic factors (Suresh, Mohandas 1990). The total number of hemocytes decreased during the season. This might be a consequence of higher need for hemocytes during early spring and after hibernation, because hemocytes are involved in many physiological processes, like production of cytotoxic molecules (Humphries, Yoshino 2008), nerve reparation (Hermann et al. 2005) and shell formation
(Mount et al. 2004), which are all evident after hibernation period.

Our results present the first data on the number of hemocytes in Roman snail (Helix pomatia). Seasonal variations such as altitude and humidity have a major impact on the production of hemocytes. The production of hemocytes increased according to physiological needs after hibernation. Three types of hemocytes were identified. Hemocytes play an important role in phagocytosis, according to the presence of transformed hemocytes and their encapsulation during infection. The uniform classification of hemocytes and detailed study of their role in the immune response can improve the knowledge of the adaptive mechanisms of other biologically important molluscs and contribute to a better organization in this field of research.

\section{References}

Accorsi A., Bucci L., de Eguileor M., Ottaviani E., Malagoli D. 2013. Comparative analysis of circulating hemocytes of the freshwater snail Pomacea canaliculata. Fish Shellfish Immunol. 34: 1260-1268.

Ataev G.L., Coustau C. 1999. Cellular response to Echinostoma caproni infection in Biomphalaria glabrata strains selected for susceptibility/resistance. Dev. Comp. Immunol. 23: 187-198.

Barracco M.A., Steil A.A., Gargioni R. 1993. Morphological characterization of the hemocytes of the pulmonate snail Biomphalaria tenagophila. Mem. Inst Oswaldo Cruz. 88: 73-83.

Battistella S., Bonivento P., Amirante G.A. 1996. Hemocytes and immunological reactions in crustaceans. Ital. J. Zool. 63: 337343.

Boisseaux P., Delignette-Muller M.L., Abbaci K., Thomas H., Garric J. 2016. Analysis of hemocytes in Lymnaea stagnalis: Characterization and effects of repeated hemolymph collections. Fish Shellfish Immunol. 57: 116-126.

Castellanos-Martínez S., Prado-Alvarez M., Lobo-da-Cunha A., Azevedo C., Gestal C. 2014. Morphologic, cytometric and functional characterization of the common octopus (Octopus vulgaris) hemocytes. Dev. Comp. Immunol. 44: 50-58.

Cavalcanti M.G., Filho F.C., Mendonça A.M., Duarte G.R., Barbosa C.C., De Castro C.M., Alves L.C., Brayner F.A. 2012. Morphological characterization of hemocytes from Biomphalaria glabrata and Biomphalaria straminea. Micron 43: 285-291.

Cossarizza A., Pinti M., Troiano L., Cooper E.L. 2005. Flow cytometry as a tool for analyzing invertebrate cells. Invertebr. Surv. J. 2: 32-40.

Cueto J.A., Rodriguez C., Vega I.A., Castro-Vazquez A. 2015. Immune defenses of the invasive apple anail Pomacea canaliculata (Caenogastropoda, Ampullariidae): Phagocytic hemocytes in the circulation and the kidney. PLoS One 10: e0123964.

Donaghy L., Hong H.K., Lambert C., Park H.S., Shim W.J., Choi K.S. 2010. First characterisation of the populations and immune-related activities of hemocytes from two edible gastropod species, the disk abalone, Haliotis discus discus and the spiny top shell, Turbo cornutus. Fish Shellfish Immunol. 28: 87-97. 
Gagnaire B., Duchemin M., Auffret M., Thomas-Guyon H., Renault T. 2008. Comparison of hemocyte parameters in the pericardial cavity and the adductor muscle sinus in the Pacific oyster, Crassostrea gigas using two types of flow cytometers. Aquat. Living Resour. 21: 39-43.

Hermann P.M., Nicol J.J., Nagle G.T., Bulloch A.G., Wildering W.C. 2005. Epidermal growth factor-dependent enhancement of axonal regeneration in the pond snail Lymnaea stagnalis: role of phagocyte survival. J. Comp. Neurol. 492: 383-400.

Humphries J.E., Yoshino T.P. 2008. Regulation of hydrogen peroxide release in circulating hemocytes of the planorbid snail Biomphalaria glabrata. Dev. Comp. Immunol. 32: 554562.

Jemaa M., Cavelier P., Cau J., Morin N. 2014. Adult somatic progenitor cells and hematopoiesis in oysters. J. Exp. Biol. 1: 3067-3077.

Karuthapandi M. 2010. Studies on the hemocytes of Achatina fulica. Indian J. Multidisciplin. Res. 6: 207-214.

Liang S., Seto E.Y.W., Remais J.V., Zhong B., Yang C., Hubbard A., Davis G.M., Gu X., Qiu D., Spear R.C. 2007. Environmental effects on parasitic disease transmission exemplified by schistosomiasis in western China. Proc. Natl. Acad. Sci. USA 104: 7110-7115.

Littlewood D.T.J., Bray R.A. 2001. Interrelationships of the Platyhelminthes. Systematics Association Special Volume Series 60. Taylor \& Francis, London and New York.

Loker E.S. 2010. Gastropod immunobiology. Adv. Exp. Med. Biol. 708: 17-43.

Malagoli D. 2018. Going beyond a static picture: the apple snail Pomacea canaliculata can tell us the life history of molluscan hemocytes. Invertebr. Surv. J. 15: 61-65.

Martin G.G., Christopher T.O., Heather R.T., Heather C., Yamakawa R. 2007. Structure and function of haemocytes in two marine gastropods, Megathura crenulata and Aplysia californica. J. Moll. Stud. 4: 355-365.

Matozzo V., Gagné F. 2016. Immunotoxicology approaches in ecotoxicology. In: Ballarin L., Cammarata M. (eds) Lessons in Immunity From Single-Cell Organisms to Mammals. Academic Press of Elsevier, Amsterdam, pp. 29-51.
Matricon-Gondran M., Letocart M. 1999. Internal defenses of the snail Biomphalaria glabrata. J. Invertebr. Pathol. 74: 224-234.

Molnar N., Fong P.P. 2012. Toxic effects of copper, cadmium, and methoxychlor shown by neutral red retention assay in two species of freshwater molluscs. Open Environ. Pollut. Toxicol. J. 3: 65-71.

Mount A.S., Wheeler A.P., Paradkar R.P., Snider D. 2004. Hemocyte-mediated shell mineralization in the Eastern oyster. Science 304: 297-300.

Oliveira A.L.D., Levada P.M., Zanotti-Magalhaes E.M., Magalhães L.A., Ribeiro-Paes J.T. 2010. Differences in the number of hemocytes in the snail host Biomphalaria tenagophila, resistant and susceptible to Schistosoma mansoni infection. Genet. Mol. Res. 9: 2436-2445.

Pila E.A., Sullivan J.T., Wu X.Z., Fang J., Rudko S.P., Gordy M.A. 2016. Hanington P.C. 2016. Haematopoiesis in molluscs: a review of haemocyte development and function in gastropods, cephalopods and bivalves. Dev. Comp. Immunol. 58: 119-128.

Sahaphong S., Linthong V., Wanichanon C., Riengrojpitak S., Kangwanrangsan N., Viyanant V., Upatham S., Pumthong T., Chansue N., Sobhon P. 2001. Morphofunctional study of the hemocytes of Haliotis asinina. J. Shellfish Res. 20: 711-716.

Smith V.J., Accorsi A., Malagoli D. 2016. Hematopoiesis and hemocytes in pancrustacean and molluscan models. In Malagoli D. (ed) The Evolution of The Immune System: Conservation and Diversification. Academic Press of Elsevier, Amsterdam, pp. 1-28.

Suljević D., Muhić A., Islamagić E., Fočak M. 2017. Temporal dependence between hibernation and posthibernation period according to biochemical profile of hemolymph in Helix pomatia Linnaeus, 1758. Acta Biol. Szeged. 61: 129-134.

Suresh K., Mohandas A. 1990. Number and types of hemocytes in Sunetta scripta and Villortia cyprinoids var. cochinensis (Bivalvia) and leukocytosis subsequent to bacterial challenge. J. Invertebr. Pathol. 55: 312-318.

Volety A.K., Winstead J.T., Fisher W.S. 1999. Influence of seasonal factors on oyster hemocyte killing of Vibrio parahemolyticus. National Shellfisheries Association Annual Meeting, U.S. Environmental Protection Agency: 92816. 